\title{
Neralsia splendens (Borgmeier) (Hymenoptera: Figitidae) como inimigo natural de Cyrtoneurina pararescita (Couri) (Diptera: Muscidae).
}

Carlos Henrique Marchiori ${ }^{1}$

1 Ins tituto Federal Goiano 


\section{JP-TSP Instituto de Patologia Tropical e Saúde Pública}

Neralsia splendens (Borgmeier) (Hymenoptera: Figitidae) como inimigo natural de Cyrtoneurina pararescita (Couri)

(Diptera: Muscidae).

Marchiori, C.H. ${ }^{1}$; Borges, L.M.F. ${ }^{2}$; Ferreira, L.L. ${ }^{3}$.

1-Professor do Instituto Federal Goiano em cooperação Técnica com Universidade Federal de Goiás/ Instituto de Patologia Tropical e Saúde Pública.

2-Instituto de Patologia Tropical e Saúde Pública/UFG

3- Mestrado em Parasitologia Veterinária/UFG

\section{INTRODUÇÃO}

Os parasitoides são responsáveis pela redução da população de moscas que proliferam em varios substratos. $A$ avaliaçäo dessas especies no controle natural destes insetos e importante para a conduçāo de estudos que visem posterior seleção para serem utilizadas em programas de controle biológico (MARCHIORI et al., 2000).

Sabe-se que a superfamilia Cynipoidea apresenta cerca de $\mathbf{2 0 . 0 0 0}$ espécies sendo que, aproximadamente, $75,0 \%$ são parasitoides de insetos holometabolos (GAULD; BOLTON, 1988). Os Figitinae comportam-se como parasitoides primários de larvas de dipteros que se desenvolvem em fezes bovinas. Na regiăo Neotropical, poucos estudos têm sido realizados com esse grupo (DIAZ-GALLARDO, 1995; 1996). Segundo Pujade-Vilar et al. (2006), o gênero Neralsia tem potencial para o controle biológico de pragas.

O objetivo deste trabalho e relatar o novo hospedeiro para Neralsia splendens (Borgmeier, 1935) (Hymenoptera: Figitidae).

\section{MATERIAL E MÉTODOS}

O experimento foi realizado nas pastagens e currais da Escola de Veterinária da Universidade Federal de Goiás, no município de Goiânia (Latitude $16^{\circ} 40^{\prime} \mathrm{S}$; Iongitude $49^{\circ} 16^{\prime \prime} \mathrm{W}$ ), região central do Estado de Goiás. Quinzenalmente, 10 placas de bolo fecal (de aproximadamente $3 \mathrm{~kg}$ cada) de fezes frescas de bovinos foram coletadas, imediatamente, após sua emissão nas pastagens de Elas foram colocadas em baldes plásticos e homogeneizadas. Em seguida, as fezes foram colocadas dentro de 10 suportes redondos, de plástico, de $20 \mathrm{~cm}$ de diâmetro, com um furo para escoar a água proveniente da chuva. Esta metodologia foi utilizada para determinação precisa do tempo entre a emissão do bolo fecal e a sua coleta. As fezes permaneceram expostas, sendo cinco nas pastagens e cinco nos currais, por quinze dias. Após este periodo, as fezes foram levadas ao laboratório para a extração das pupas, pelo método da flotacão. As pupas foram retiradas com o auxilio de uma peneira contadas e individualizadas em cápsulas de gelatina (número 00), até a emergência das moscas e/ou dos parasitoides. Os parasitoides e as moscas emergidos, identificados com auxilio de um microsćpio estereoscópio foram conservados em álcool $70 \%$. um mic A identificacão dos parasitoides adultos foi realizada utilizando chaves identificação de Diaz-Gallardo (1995) e dos hospedeiros, conforme Carvalho et al. (2002). A porcentagem de parasitismo foi pupas coletadas $x$ do

\section{RESULTADOS E DISCUSSÃO}

No período de março a julho de 2012, foram coletadas 26 pupas de Cyrtoneurina pararescita (Couri, 1995) (Diptera: Muscidae) (Figura 2) em fezes bovinas, das quais emergiram dois espécimes de $N$. splendens (Figura1). A taxa de parasitismo foi de $0,35 \%$.

Neralsia splendens foi coletada em pupas de Sarcophagula occidua (Fabricius, 1794) (Diptera: Sarcophagidae), tanto no Brasil quanto na Argentina ((DíAZ-GALLARDO, 1996; MARCHIORI; LINHARES, 1999; MARCHIORI, 2000; MARCHIORI et al., 2000; 2003)
No Brasil, em fezes bovinas, $C$. pararescita foi encontrada arasitada pelos seguintes parasitoides: Pachycrepoideus vindemmiae (Rondani) (Hymenoptera: Pteromalidae) (MARCHIORI; SIVA FILHO, 2007), Paraganaspis egeria (Hymenoptera: Figitidae), Spalangia nigra Latrielle e Spalangia nigroaenea Curtis (Hymenoptera: Pteromalidae) (MARCHIORI et al., 2007).

Este trabalho relata a ocorrência $N$. splendens parasitando C. pararescita no mundo.

\section{REFERÊNCIAS}

CARVALHO, C. J. B; MOURA, M. O; RIBEIRO, P. B. Cheve para adultos de dipteros (Muscidae, Fanniidae,
Anthomyiidae) associados ao ambiente humano no Brasil. Revista Brasilera de Entomologia, Curniba, v. 46, n. 2, . . 107-114, 2002

DIAZ, N: GALLARDO, F. Aportes al conocimiento de Nerelsia splendens en la Argentina (Hymenoptera:
Figitidae) Revista da Sociedad Entomológica Argentina, Buenos Aires, v. 54, . . 74, 1995. DiAZ, N. GALLARDO, F. Sobre cinipoideos del Brasil, parasitoides de dipteros estercoleros (Hymenoptera:
Cynipoodea). Revista da Sociedad Entomologica Argentina, Buenos Aires, v. 55, n. 1-4, p. 127-129, 1996. GAULD. I. D. BOLTON. B. The Hymenoptera. Oxford: Oxford University, 1988. 331p

MARCHORI, C. H. parasitolides de estágios imaturos de dipteros sinantropicos coletadós em város

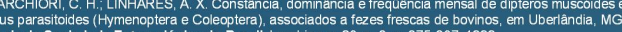

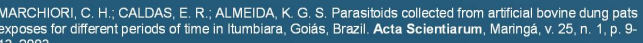

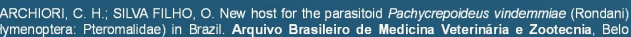
Horizonte,, . 59, n. . 1, p. 271-272, 2007.

ARCHIORI, C. H. SILVAFLLHO, O. MLLHOMEM, M. E. V: LELES, A. S. Parasitodes de dipteros coletado fezes de bứalos em uma propriedade rural em ltumbiara, Goias,
veterinária e Zootecnia, Belo Horizonte, v. 59, n. 6, p. 1589-1592, 2007.

WRCHIORI, C. H. VIEIRA, C. I. S: CALDAS, E. R. TEIXEIRA, F, F, SILVA, C, G, LINHARES, A. X.

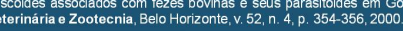

PUJADE-VLAR, J., PARETAS-MARTINEZ, J., JMEÉNEZ, M. Description of a new species of Nerelsia

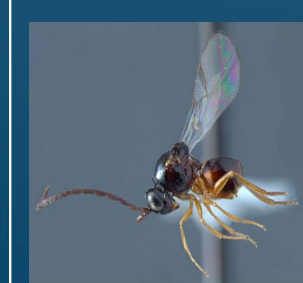

Figura 1- Neralsia splendens

Figura 2 - Cyrtoneurina pararescita

Figure 